\title{
COMPARISON OF EPIDURAL BUPIVACAINE; FENTANYL AND THEIR COMBINATION FOR POSTOPERATIVE ANALGESIA IN LOWER ABDOMINAL AND LOWER EXTREMITY SURGERY: A PROSPECTIVE, RANDOMIZED, DOUBLE BLIND CONTROLLED TRIAL
}

\author{
Purba Haldar1, Sushil Kumar Nayak2, Amit Ray33, Himendra Kumar Roy4, Saswati Pal5, Jaydeb Ray6, Sujata Ghosh ${ }^{7}$, \\ Dhurjoti Prasad Bhattacharya ${ }^{8}$ \\ ${ }_{1}^{1}$ Assistant Professor, Department of Anaesthesiology, Calcutta National Medical College. \\ ${ }^{2}$ Associate Professor, Department of Anaesthesiology, Calcutta National Medical College. \\ ${ }^{3}$ Assistant Professor, Department of Surgery, IPGME \& R, Kolkata. \\ ${ }^{4}$ R.M.O. Cum Clinical Tutor, Department of Anaesthesiology, Calcutta National Medical College. \\ ${ }_{5}^{5}$ Associate Professor, Department of Anaesthesiology, NRSMC \& H. Kolkata. \\ ${ }^{6}$ Associate Professor, Department of Anaesthesiology, Calcutta National Medical College. \\ ${ }^{7}$ Assistant Professor, Department of Anaesthesiology, Calcutta National Medical College. \\ ${ }^{8}$ Professor, Department of Anaesthesiology, Calcutta National Medical College.
}

\section{ABSTRACT}

\section{BACKGROUND}

Epidural analgesia with local anaesthetics and opioids provide good control of postoperative pain in lower abdominal and lower extremity surgery.

\section{AIM}

To evaluate and compare the analgesic action and adverse effects of epidural bupivacaine, fentanyl and their combination in postoperative period.

\section{METHODS}

75 patients undergoing elective infraumbilical surgery were allocated in three groups in a randomized double blinded fashion. Postoperative analgesia was maintained with continuous infusion of epidural drug in the following manner: Group B: Injection Bupivacaine $0.125 \% @ 0.1 \mathrm{~mL} / \mathrm{kg} / \mathrm{hr}$ through epidural route; Group F: Injection Fentanyl $4 \mu \mathrm{g} / \mathrm{mL} @ 0.1 \mathrm{~mL} / \mathrm{kg} / \mathrm{hr}$ through epidural route; Group BF: Injection Bupivacaine $0.0625 \%$ and Fentanyl $2 \mu / \mathrm{mL} @ 0.1 \mathrm{~mL} / \mathrm{kg} / \mathrm{hr}$ through epidural route.

\section{RESULTS}

VAS score were almost similar in all three groups at $00,04,08 \mathrm{hrs}$ and not clinically significant at that point of time. VAS score showed significant difference at 12, 20 and $24 \mathrm{hrs}$, being persistently lower in Gr BF than Gr B and Gr F. According to VRS Scale Score at $04 \mathrm{hrs}$ majority of patients of all three groups had mild-to-moderate pain ( $\mathrm{p}=0.278$ ). At $08 \mathrm{hrs}, 24 \%$ ( $\mathrm{p}=0.082$ ), $12 \mathrm{hrs} 60 \%$ (<0.001), $16 \mathrm{hrs} 68 \%(<0.001), 20 \mathrm{hrs} 88 \%$ (<0.001) and $24 \mathrm{hrs} 84 \%(<0.001)$ of Gr BF patients were pain free which are clinically significant. At the end of $08,12,16,20,24$ postoperative hours, no patients of any groups had residual motor paralysis. Rescue analgesic needed in Gr BF patients were significantly less than other two groups.

\section{CONCLUSION}

Combined bupivacaine and fentanyl infusion through an epidural route provides better analgesia in comparison to bupivacaine and fentanyl alone. Total drug, rescue analgesic requirement and adverse effects are much lower in combined group.

\section{KEYWORDS}

Postoperative Analgesia, Epidural Infusion, Bupivacaine, Fentanyl, Combination.

HOW TO CITE THIS ARTICLE: Haldar P, Nayak SK, Ray A, et al. Comparison of epidural bupivacaine; fentanyl and their combination for postoperative analgesia in lower abdominal and lower extremity surgery: a prospective, randomized, double blind controlled trial. J. Evolution Med. Dent. Sci. 2016;5(22):1146-1151, DOI: 10.14260/jemds/2016/267

\section{INTRODUCTION}

Acute post-operative pain is a complex physiologic reaction to tissue injury, visceral distention or disease, which results in patient specific unpleasant, unwanted sensory and subjective emotional experience. ${ }^{1}$

The epidural route for analgesia has been used much more extensively for postoperative pain management. It provides the advantage of prolonging the analgesia with an epidural catheter using epidural local anaesthetic drug and

Financial or Other, Competing Interest: None.

Submission 18-02-2016, Peer Review 02-03-2016,

Acceptance 05-03-2016, Published 15-03-2016.

Corresponding Author:

Purba Haldar,

Flat: L-3, Block: IV,

Swabhumi Residency, P-12,

Motijheel Avenue,

Kolkata-74.

E-mail: purbahaldar@gmail.com

DOI: $10.14260 /$ jemds $/ 2016 / 267$ opioids, freedom from the risk of post lumbar puncture headache, positive respiratory, cardiovascular and neuroendocrine effects, blunt the stress response to surgery, reduce thromboembolic complication and blood loss, thus improve the quality of life, augment functionality, enhance activities of daily living and reduce physiological and emotional morbidity.

Epidural local anaesthetics and opioid when used in combination, they provide analgesia acting at two distinct sites - LA at nerve axons and opioid at the $\mu$ receptor at substantia gelatinosa of spinal cord.

Nerve fibers are categorized into three classes (A, B \& C), depending on size, degree of myelination, rapidity of conduction and distribution of fibers. Functional division of the class fibers are into the subtype alpha, beta, gamma and delta. Type $\mathrm{A}^{\delta}$ and type $\mathrm{C}$ fibers which carries pain sensation are more sensitive to local anaesthetic drug. Progression of anaesthesia is also related to the diameter, myelination and conduction velocities of the affected nerve. Clinically, the order 
of loss of nerve function-Pain, temperature, touch, proprioception and skeletal muscle tone.

Differential block refers to a clinically important phenomenon, in which nerve fibers subserving different functions display varying sensitivity to local anaesthetic blockade. This is solely explained by differences in fiber diameter with small diameter neurons exhibiting greater sensitivity than larger diameter neurons. There is selective blockade of preganglionic sympathetic nervous system B fibers using low concentration of local anaesthetics. Slightly higher concentration of local anaesthetics interrupt conduction in small $\mathrm{C}$ fibers and small and medium sized $\mathrm{A}$ fibers with loss of sensation of pain and temperature. Nevertheless touch, proprioception and motor function are still present.

For postoperative analgesia, local anaesthetic drug and opioid combination are used in very low concentration. At this low concentration, drug will produce adequate analgesia without sympathetic or motor block and will allow the patient to remain ambulatory without any risk of orthostatic hypotension.

Fentanyl, a highly lipid-soluble drug, when administered epidurally is released in the cerebrospinal fluid very slowly and there is less chance of sedation and respiratory depression. 2,3

Our aim is to study the effectiveness of postoperative epidural analgesia with either Bupivacaine $(0.125 \%)$ or Fentanyl $(4 \mu / \mathrm{ml})$ alone or the combination (Bupivacaine $0.0625 \%)$ and Fentanyl $(2 \mu / \mathrm{mL})$ in 75 patients after lower abdominal and lower extremity surgery.

\section{METHODS}

This prospective, double blind, randomized clinical study was conducted in the Orthopaedic and Surgical Operation Theatre and Post Anaesthetic Care Unit. Ethical clearance was obtained from the Institutional Ethical Committee.

75 patients of ASA I and II, aged between 25-55 years, body weight between $50-70 \mathrm{~kg}$ and height $160 \pm 10 \mathrm{~cm}$ undergoing lower abdominal and orthopaedic surgery in lower extremity were observed for a period of 1 year. The patients were without any apparent cardiovascular, respiratory, neurological disorder and known allergy to local anaesthetic drug.

The patients who could not understand the Visual Analogue Scale and who refused the technique of epidural analgesia were excluded from our study.

On previous night before surgery, all patients received Tab Diazepam (10mg). Inj. Metoclopramide (10mg), Injection Ranitidine (50mg) IV/IM was administered 1 to 2 hours before operation. Patients were taken to the operating room and multichannel monitors for non-invasive blood pressure, partial saturation of oxygen and electrocardiography were applied.

After proper antiseptic dressing and draping, epidural catheter was introduced through L3-4 interspace, catheter secured and fixed in proper position and patient was turned supine.

Surgery was done under epidural anaesthesia with Injection bupivacaine $0.5 \%(2 \mathrm{mg} / \mathrm{kg})$ in incremental dose and patients requiring any supplementation of other anaesthetic agent during surgery were excluded from the study.
After completion of the surgical procedure, patients were transferred to postoperative care unit and were randomly allocated into one of the three groups by block randomization using computer assignment, 25 patients in each group and labelled them as Group B, Group F and Group BF.

In the postoperative period, the patients of different groups received continuous epidural drug infusion in following manner:

Group B: Received Injection Bupivacaine $0.125 \%$ @ $0.1 \mathrm{~mL} / \mathrm{kg} / \mathrm{hr}$.

Group F: Received Injection Fentanyl $4 \mu \mathrm{g} / \mathrm{mL} @ 0.1 \mathrm{~mL} / \mathrm{kg} / \mathrm{hr}$ Group BF: Received Injection Bupivacaine $0.0625 \%$ and Fentanyl $2 \mu / \mathrm{mL} @ 0.1 \mathrm{~mL} / \mathrm{kg} / \mathrm{hr}$.

Drugs were prepared and dispensed in similar looking syringes, coded by hospital pharmacy and the nature of the drug was concealed by the pharmacy. Separate assessors who were unaware of the drug administered observed the patients in the postoperative period.

Haemodynamic parameters (Pulse rate, systolic and diastolic blood pressure, respiratory rate, partial saturation of oxygen), postoperative analgesia (Visual Analogue Scale Score, $0-10 \mathrm{~cm}, 0=$ no pain, $10=$ worst pain possible), Degree of motor block (Modified Bromage scale, 0-no paralysis, 1-inability to raise extended leg, 2-inability to flex knee, 3-inability to flex ankle and first toe). Duration of analgesia (Four point verbal rating scale to record the observer assessment of pain). The scores are: i) Comfortable (No pain); ii) Mild pain (Only elicited by close questioning); iii) Moderate pain (Bothering the patient, but often controlled by lying still, analgesic accepted gladly); iv) Severe pain (Dominating the consciousness and calling out for urgent relief) and adverse effects (Nausea, vomiting, headache, pruritus, respiratory depression, hypotension, shivering, urinary retention, drowsiness) were also noted in postoperative period for 24 hours.

When the patients complained of pain he/she was asked by the assessor to put a mark on the Visual Analogue Scale to indicate the intensity of pain felt. Rescue analgesic was administered (Inj. Tramadol $2 \mathrm{mg} / \mathrm{kg}$ IV) in case of visual analogue scale score of 4 .

\section{RESULTS}

All the demographic data, types of operation, postoperative haemodynamic parameters like heart rate, respiratory rate, systolic and diastolic blood pressure, visual analogue scale score, verbal rating scale score, rescue analgesic required and adverse effects were analysed according to appropriate statistical methods. One Way Analysis of Variance (ANOVA), Tukey's post hoc test, Chi square test, Kruskal-Wallis Test were performed for inter and intragroup comparison.

Comparison between these three groups by One-way Analysis of Variance (ANOVA) showed that age ( $F=0.138$, $\mathrm{p}=0.872)$, Weight $(\mathrm{F}=1.465, \mathrm{p}=.238)$ and Height $(\mathrm{F}=.324$, $\mathrm{p}=.724)$, Sex $(\mathrm{p}=0.832)$, ASA status $(\mathrm{p}>0.05)$ were comparable (Table 1).

Regarding types of operation performed and the duration of procedure, all the patients of all three groups were comparable and there were no significant statistical difference ( $x 2$ p 0.998).

A significant difference in the Heart rate between the three groups was found by ANOVA at $4 \mathrm{hr}(\mathrm{F}=3.326$, $\mathrm{p}=0.042)$, $8 \mathrm{hr}(\mathrm{F}=3.519, \mathrm{p}=.035)$ and $20 \mathrm{hr}(\mathrm{F}=5.697, \mathrm{p}=.005)$. 
At $4^{\text {th }}$ and $8^{\text {th }}$ postoperative hour, Heart rate in $\mathrm{F}$ group was greater than in combined group. At $20^{\text {th }}$ hour, HR in B group was greater $(\mathrm{p}=0.004)$ than the combined group. These comparisons were done by Tukey's post hoc test.

Comparison between the three groups by ANOVA showed that there was a significant difference in Systolic Blood Pressure at time points of $08 \mathrm{hr}(\mathrm{F}=5.437, \mathrm{p}=.006), 12$ hour $(\mathrm{F}=37.746, \mathrm{p}=.000), 16$ hour $(\mathrm{F}=54.813, \mathrm{p}=.000), 20$ hour $(\mathrm{F}=79.366, \mathrm{p}=.000)$ and 24 hour $(\mathrm{F}=71.928, \mathrm{p}=.000)$.

Tukey's post hoc test showed that systolic blood pressure was consistently lower in the combined group than the Bupivacaine and Fentanyl group at all-time point from 08 hours to 24 hours $(\mathrm{p}<0.01)$ in all cases. There was no significant difference between Bupivacaine and Fentanyl group.

Comparison between the three group by ANOVA showed that there was a significant difference in diastolic blood pressure at time points of 04 hour $(\mathrm{F}=17.145, \mathrm{p}=.000), 08$ hour $(\mathrm{F}=5.932, \mathrm{p}=.004), 12$ hour $(\mathrm{F}=3.351, \mathrm{p}=.041), 20$ hour $(\mathrm{F}=8.153, \mathrm{p}=.001)$ and at 24 hour $(\mathrm{F}=30.855, \mathrm{p}=.000)$. Difference was not significant at 16 hour $(\mathrm{F}=2.325$, $\mathrm{p}=.105)$.

Tukey's post hoc test showed that the diastolic blood pressure in the combined group is significantly lower than in Bupivacaine or Fentanyl group ( $\mathrm{p}<.01)$ in both the cases - at 0 hour, 08 hour as well as at 24 hours. There was no difference between Bupivacaine and Fentanyl group. Difference at 16 hours was not statistically significant.

In respiratory rate and partial saturation of oxygen, although there were isolated changes at a few time points, there was no difference clinically and statistically.
Comparison between the three group by ANOVA showed that there was a significant difference in Visual Analogue Scale Score at time points of 08 hour ( $F=23.266, p=.000), 12$ hour ( $\mathrm{F}=15.938, \mathrm{p}=.000), 16$ hour $(\mathrm{F}=58.320, \mathrm{p}=.000), 20$ hour $(\mathrm{F}=113.468, \mathrm{p}=.000)$ and 24 hour $(\mathrm{F}=200.280, \mathrm{p}=.000)$.

Tukey's post hoc test showed that Visual Analogue Scale Score was consistently lower in the combined group than the Bupivacaine and Fentanyl group at all-time point from 08 hour to 24 hour $(\mathrm{p}<0.001)$ in all cases. There was no significant difference between Bupivacaine and Fentanyl group.

At the end of 8 hour, $56 \%$ of the group B patients, $44 \%$ of the group $\mathrm{F}$ patients and $52 \%$ of the combined group patients complained of mild pain. Only $36 \%$ patients of combined group were pain free at that time point. $\chi 2 \mathrm{P}$ value at 0 hour 0.128 , at 8 hour $<0.001$, at 12 hour $<0,001$.

At the end of 16 hours $92 \%$ patients of combined group were pain free, but only $12 \%$ patients of group $\mathrm{F}$ and none of the patients of group B were pain free at that time. $\chi 2 \mathrm{P}$ value at 16 hour $<0.001$, at 20 hour $<0.001$, at 24 hour $<0.001$.

At 24 hours, none of the patients of combined group complained of any pain and patients of isolated drug group complained of mild-to-moderate pain and some of them asked for rescue analgesic.

Rescue analgesic needed in combination group was much more less than the Bupivacaine and Fentanyl only group. All the adverse effects (Nausea, vomiting, hypotension, shivering, drowsiness, pruritus, respiratory depression and urinary retention) were minimal among three groups.

\begin{tabular}{|c|c|c|c|c|c|c|}
\hline Group & & Age (yrs) & Weight (kg) & Height (cm) & Sex (M:F) & ASA I/II \\
\hline B & Mean \pm SD & $47.320 \pm 8.956$ & $65.200 \pm 4.813$ & $157.560 \pm 4.933$ & $9: 16$ & $16: 9$ \\
\hline F & Mean \pm SD & $46.800 \pm 9.814$ & $63.480 \pm 6.577$ & $157.760 \pm 4.960$ & $7: 18$ & $19: 6$ \\
\hline BF & Mean \pm SD & $45.960 \pm 8.941$ & $62.320 \pm 6.407$ & $156.720 \pm 4.641$ & $8: 17$ & $12: 13$ \\
\hline \multicolumn{7}{|c|}{ Table 1: Demographic Profile } \\
\hline
\end{tabular}

\begin{tabular}{|c|c|c|c|c|c|c|c|}
\hline Group & $\begin{array}{c}\text { HR00 } \\
\text { Mean } \pm \text { SD }\end{array}$ & $\begin{array}{c}\text { HR04 } \\
\text { Mean } \pm \text { SD }\end{array}$ & $\begin{array}{c}\text { HR08 } \\
\text { Mean } \pm \text { SD }\end{array}$ & $\begin{array}{c}\text { HR12 } \\
\text { Mean } \pm \text { SD }\end{array}$ & $\begin{array}{c}\text { HR16 } \\
\text { Mean } \pm \text { SD }\end{array}$ & $\begin{array}{c}\text { HR20 } \\
\text { Mean } \pm \text { SD }\end{array}$ & $\begin{array}{c}\text { HR24 } \\
\text { Mean } \pm \text { SD }\end{array}$ \\
\hline B & $102.48 \pm 8.780$ & $99.92 \pm 6.867$ & $100.40 \pm 6.429$ & $100.080 \pm 7.152$ & $99.360 \pm 4.498$ & $101.280 \pm 7.764$ & $100.800 \pm 6.976$ \\
\hline F & $103.40 \pm 10.79$ & $103.440 \pm 7.583$ & $102.320 \pm 9.104$ & $100.640 \pm 10.144$ & $99.040 \pm 8.208$ & $97.280 \pm 7.368$ & $98.320 \pm 6.944$ \\
\hline BF & $104.08 \pm 8.971$ & $98.000 \pm 8.185$ & $96.320 \pm 8.711$ & $95.840 \pm 8.924$ & $95.920 \pm 8.030$ & $94.560 \pm 5.986$ & $96.400 \pm 6.027$ \\
\hline \multicolumn{7}{|c}{ Table 2: Shows the Mean and Standard Deviation of Post-operative Heart Rate at Different Time } \\
\hline
\end{tabular}

\begin{tabular}{|c|c|c|c|c|c|c|c|}
\hline Group & $\begin{array}{c}\text { SBP00 } \\
\text { Mean } \pm \text { SD }\end{array}$ & $\begin{array}{c}\text { SBP04 } \\
\text { Mean } \pm \text { SD }\end{array}$ & $\begin{array}{c}\text { SBP08 } \\
\text { Mean } \pm \text { SD }\end{array}$ & $\begin{array}{c}\text { SBP12 } \\
\text { Mean } \pm \text { SD }\end{array}$ & $\begin{array}{c}\text { SBP16 } \\
\text { Mean } \pm \text { SD }\end{array}$ & $\begin{array}{c}\text { SBP20 } \\
\text { Mean } \pm \text { SD }\end{array}$ & $\begin{array}{c}\text { SBP24 } \\
\text { Mean } \pm \text { SD }\end{array}$ \\
\hline $\mathrm{B}$ & $126.560 \pm 8.010$ & $125.040 \pm 7.662$ & $123.760 \pm 9.097$ & $128.240 \pm 6.50$ & $126.800 \pm 5.859$ & $128.480 \pm 6.436$ & $127.920 \pm 4.881$ \\
\hline $\mathrm{F}$ & $127.120 \pm 5.068$ & $126.160 \pm 4.506$ & $125.200 \pm 5.099$ & $124.96 \pm 4.513$ & $124.960 \pm 4.730$ & $126.800 \pm 4.320$ & $126.880 \pm 3.370$ \\
\hline $\mathrm{BF}$ & $128.400 \pm 4.690$ & $123.440 \pm 4.565$ & $119.360 \pm 4.348$ & $115.04 \pm 5.541$ & $112.160 \pm 5.505$ & $111.520 \pm 4.735$ & $114.320 \pm 5.022$ \\
\hline \multicolumn{6}{|c|}{ Table 3: Shows that Mean and Standard Deviation of Post-operative Systolic Blood Pressure at Different Hours } \\
\hline
\end{tabular}

\begin{tabular}{|c|c|c|c|c|c|c|c|}
\hline Group & $\begin{array}{c}\text { DBP00 } \\
\text { Mean } \pm \text { SD }\end{array}$ & $\begin{array}{c}\text { DBP04 Mean } \pm \\
\text { SD }\end{array}$ & $\begin{array}{c}\text { DBP08 Mean } \pm \\
\text { SD }\end{array}$ & $\begin{array}{c}\text { DBP12 Mean } \pm \\
\text { SD }\end{array}$ & $\begin{array}{c}\text { DBP16 Mean } \pm \\
\text { SD }\end{array}$ & $\begin{array}{c}\text { DBP20 Mean } \pm \\
\text { SD }\end{array}$ & $\begin{array}{c}\text { DBP24 Mean } \pm \\
\text { SD }\end{array}$ \\
\hline B & $82.000 \pm 5.163$ & $81.440 \pm 4.882$ & $81.520 \pm 5.810$ & $82.880 \pm 4.082$ & $83.120 \pm 5.449$ & $82.560 \pm 5.339$ & $86.560 \pm 4.340$ \\
\hline F & $85.200 \pm 6.506$ & $85.280 \pm 6.215$ & $86.400 \pm 5.686$ & $86.400 \pm 3.741$ & $85.120 \pm 5.509$ & $86.120 \pm 6.053$ & $86.640 \pm 4.644$ \\
\hline BF & $93.840 \pm 10.534$ & $91.600 \pm 7.257$ & $87.280 \pm 7.458$ & $83.760 \pm 6.863$ & $81.680 \pm 6.018$ & $79.840 \pm 5.225$ & $78.160 \pm 4.160$ \\
\hline \multicolumn{7}{|c|}{ Table 4: Shows the Mean and Standard Deviation of Post-operative Diastolic Blood Pressure } \\
\hline
\end{tabular}

\begin{tabular}{|c|c|c|c|c|c|c|c|}
\hline Group & $\begin{array}{c}\text { VASO0 } \\
\text { Mean } \pm \text { SD }\end{array}$ & $\begin{array}{c}\text { VAS04 } \\
\text { Mean } \pm \text { SD }\end{array}$ & $\begin{array}{c}\text { VAS08 } \\
\text { Mean } \pm \text { SD }\end{array}$ & $\begin{array}{c}\text { VAS12 } \\
\text { Mean } \pm \text { SD }\end{array}$ & $\begin{array}{c}\text { VAS16 } \\
\text { Mean } \pm \text { SD }\end{array}$ & $\begin{array}{c}\text { VAS20 } \\
\text { Mean } \pm \text { SD }\end{array}$ & $\begin{array}{c}\text { VAS24 } \\
\text { Mean } \pm \text { SD }\end{array}$ \\
\hline B & $2.680 \pm 0.476$ & $2.920 \pm 1.037$ & $3.400 \pm 0.912$ & $3.400 \pm 1.471$ & $3.480 \pm 1.045$ & $3.560 \pm 0.768$ & $3.960 \pm 0.888$ \\
\hline $\mathrm{F}$ & $2.360 \pm 0.637$ & $2.520 \pm 0.918$ & $3.720 \pm 0.936$ & $3.160 \pm 1.067$ & $3.240 \pm 1.300$ & $3.080 \pm 1.037$ & $3.920 \pm 0.996$ \\
\hline $\mathrm{BF}$ & $2.640 \pm 0.489$ & $2.480 \pm 0.770$ & $1.960 \pm 1.059$ & $1.480 \pm 1.357$ & $0.640 \pm 0.637$ & $0.400 \pm 0.500$ & $0.080 \pm 0.276$ \\
\hline \multicolumn{8}{|c|}{ Table 5: Shows the Mean and Standard Deviation of Visual Analogue Scale Score at Different Post-operative Hour } \\
\hline
\end{tabular}




\begin{tabular}{|c|c|c|c|c|c|c|c|c|c|}
\hline & \multicolumn{3}{|c|}{ VRS 0 hour } & \multicolumn{3}{c|}{ VRS 8 hour } & \multicolumn{3}{c|}{ VRS 12 hour } \\
\hline & None & Mild & Mod & None & Mild & Mod & None & Mild & Mod \\
\hline B n (\%) & 0 & $25(100 \%)$ & 0 & 0 & $14(56 \%)$ & $11(44 \%)$ & $4(16 \%)$ & $9(36 \%)$ & $12(48 \%)$ \\
\hline F n (\%) & $2(8 \%)$ & $23(92 \%)$ & 0 & 0 & $11(44 \%)$ & $14(56 \%)$ & $1(4 \%)$ & $15(60 \%)$ & $9(36 \%)$ \\
\hline BF n (\%) & 0 & $25(100 \%)$ & 0 & $9(36 \%)$ & $13(52 \%)$ & $3(12 \%)$ & $15(60 \%)$ & $7(28 \%)$ & $3(12 \%)$ \\
\hline
\end{tabular}

\begin{tabular}{|c|c|c|c|c|c|c|c|c|c|}
\hline & \multicolumn{3}{|c|}{ VRS 16 hour } & \multicolumn{3}{|c|}{ VRS 20 hour } & \multicolumn{3}{|c|}{ VRS 24 hour } \\
\hline & None & Mild & Mod & None & Mild & Mod & None & Mild & Mod \\
\hline $\begin{array}{c}\text { B } \\
\text { n (\%) }\end{array}$ & 0 & $16(64 \%)$ & $9(36 \%)$ & 0 & $15(60 \%)$ & $10(40 \%)$ & 0 & $9(36 \%)$ & $15(60 \%)$ \\
\hline $\begin{array}{c}\mathrm{F} \\
\mathrm{n}(\%)\end{array}$ & 3 (12\%) & $11(44 \%)$ & $11(44 \%)$ & $1(4 \%)$ & $18(72 \%)$ & $6(24 \%)$ & 0 & $8(32 \%)$ & $17(68 \%)$ \\
\hline $\begin{array}{c}\text { BF } \\
\mathrm{n}(\%)\end{array}$ & $23(92 \%)$ & $2(8 \%)$ & 0 & $25(100 \%)$ & 0 & 0 & $25(100 \%)$ & 0 & 0 \\
\hline & $T a b$ & Compa & fVerba & ing Scale & e betwe & the thre & ups at dij & thours & \\
\hline
\end{tabular}

\begin{tabular}{|c|c|c|}
\hline Group & Rescue 0 & Rescue 1 \\
\hline & $\mathrm{n}(\%)$ & $\mathrm{n}(\%)$ \\
\hline $\mathrm{B}$ & 0 & $25(100 \%)$ \\
\hline $\mathrm{F}$ & 0 & $25(100 \%)$ \\
\hline $\mathrm{BF}$ & $17(68 \%)$ & $8(32 \%)$ \\
\hline \multicolumn{3}{|c|}{ Table 7: Requirement of Rescue } \\
Analgesic in three groups
\end{tabular}

\begin{tabular}{|c|c|c|c|}
\hline Adverse Effects & Gr B & Gr F & Gr BF \\
\hline Nausea/Vomiting & 2 & 2 & 2 \\
\hline Hypotension & 1 & 0 & 0 \\
\hline Shivering & 1 & 2 & 0 \\
\hline Drowsiness & 0 & 1 & 0 \\
\hline Pruritus & 1 & 2 & 0 \\
\hline Resp. depression & 0 & 0 & 0 \\
\hline Urinary retention & 2 & 0 & 0 \\
\hline \multicolumn{4}{|c|}{ Table 8: Shows the Incidence of } \\
Adverse Effects in all three groups \\
\hline
\end{tabular}

Chi square test 2 - tailed $\mathrm{p}$ value $<0.001$.

\section{DISCUSSION}

Analgesia delivered through an indwelling epidural catheter is a safe and effective method for management of acute postoperative pain. Studies have shown that the neuraxial administration of opioid provide profound analgesia with fewer central and systemic side effects than opioid administered systemically, particularly when local anaesthetic (Morgan M, 1989) are used.

The duration of action of epidural fentanyl is short. Excellent results have been reported with continuous infusion of fentanyl postoperative analgesia. The choice of local anaesthetic drug play a role in regional anaesthesia. In this study, bupivacaine was chosen because fentanyl added to bupivacaine decreases the requirement of local anaesthetic. This advantage of fentanyl is lost if local anaesthetic used is lignocaine (Breen 1992). Continuous epidural infusion of drugs were used to provide the postoperative analgesia for twenty four hours and also continued where necessary. This made the patient more comfortable and also made the study less expensive.

At $4^{\text {th }}$ and $8^{\text {th }}$ postoperative hour HR in Gr F were greater than HR in Gr BF. At 20th hour HR of Gr B was greater than HR in Gr BF. Systolic blood pressure was consistently lower in $\mathrm{Gr}$ $\mathrm{BF}$ than other groups at all-time point from $08 \mathrm{hrs}$ to $24 \mathrm{hrs}$.
There were significant difference in systolic blood pressure at different point of time. Diastolic blood pressure in Gr BF was significantly lower than other two groups at 04,08 , 12, 20 and 24 hours. Difference was not significant at $16 \mathrm{hrs}$. VAS score were almost similar in all three groups at 00, 04, 08 hrs and they did not show any significant difference at these point of time. VAS score showed significant difference at 12, 20 and $24 \mathrm{hrs}$, being persistently lower in $\mathrm{Gr}$ BF than $\mathrm{Gr} B$ and $\mathrm{Gr}$ F. According to Verbal Rating Scale Score at 04 hrs majority of patients of all three groups had mild-to-moderate pain ( $\mathrm{p}=0.278)$. At $08 \mathrm{hrs}, 24 \%$ ( $\mathrm{p}=0.082), 12 \mathrm{hrs} 60 \%(<0.001), 16$ hrs 68\% (<0.001), $20 \mathrm{hrs} 88 \%(<0.001)$ and $24 \mathrm{hrs} 84 \%$ $(<0.001)$ of Gr BF patients were pain free, which are clinically significant.

Rescue analgesic needed in $\mathrm{Gr}$ BF patients were significantly less in comparison to $\mathrm{Gr} B(\mathrm{P}=0.002)$ and $\mathrm{Gr} F$ $(\mathrm{P}=0.001)$.

Milon D and Coworkers. ${ }^{4}$ In 1986 found bupivacainefentanyl provide better analgesia without any clinically significant respiratory depression in mother and foetus in epidural anaesthesia for caesarean section. Sintara RS et al. 5 in 1991 in their study of labour analgesia concluded that epidurally administered fentanyl safely extend the duration of labour analgesia while reducing bupivacaine drug dose requirement and magnitude of motor block. Addition of fentanyl to extradural loading dose and subsequent infusion of local anaesthetic is a satisfactory alternative to giving higher doses of local anaesthetic alone. Copper D et al.6 in 1993 studied that in patient controlled extradural analgesia, bupivacaine and fentanyl combination provide better postoperative analgesia than either drug alone. Bander et al. ${ }^{7}$ in their study in 1994 concluded that bupivacaine improves continuous postoperative fentanyl analgesia after abdominal and thoracic surgery.

Oczan S and co-workers. ${ }^{8}$ in 2004 observed that preemptive administration of epidural fentanyl-bupivacaine combination reduces the postoperative pain and analgesic consumption in lower abdominal surgery. Continuous infusion provides effective analgesia, while reducing the side effects associated with bolus administration. El-Baz et al. ${ }^{9}$ in 1994 described that continuous epidural morphine $(100 \mu \mathrm{g} / \mathrm{hr})$ provides equivalent analgesia and fewer side effects than after epidural boluses of either bupivacaine $(0.5 \%)$ or morphine (5mg).

In our study, bupivacaine $(0.0625 \%)$ and fentanyl $(2 \mu \mathrm{g} / \mathrm{mL})$ combination provides adequate postoperative 
analgesia than either drug alone, which is consistent with all these previous studies. Continuous infusion of local anaesthetic drug with opioid has reduced the drug dose requirement, adverse effects and requirement of rescue analgesics.

Advantage of epidural administration of drugs, such as opioids and local anaesthetics include the reduced incidence of side effects and a diminished propensity for opioid induced ventilatory depression compared with the intrathecal route. When a drug is placed in the epidural space, it must first cross the dura before it can reach the spinal cord. Besides the physical barrier presented by the dura, the epidural space is highly vascularized and a significant redistribution of drug to the systemic circulation occurs. The epidural space also contains fat, connective tissues, a lymphatic network and the dorsal and ventral roots of the spinal nerves, all of which can serve as a repository for lipophilic agents.

Because the diffusion of drugs across the dura is both concentration and time dependent, it is necessary to administer significantly larger amounts of drugs than those that effectively saturate spinal opiate receptors. These higher doses are more likely to produce unwanted side effects from systemic and rostral distribution of drugs, but fewer than associated with equianalgesic intrathecal doses. When these factors are considered, the margin of therapeutic safety and the decrease in the side effects with epidural administration make this route preferred for postoperative analgesia.

Effective analgesia with epidural infusions administered at a continuous rate may take as long as 3 to 4 hours to achieve. Delay in onset of effective analgesia can be reduced by adjusting the infusion rate to provide the equivalent of a small ( 5 to $10 \mathrm{~mL}$ ) bolus of an epidural solution over 5 to 15 minutes before beginning the maintenance infusion. This allows an adequate concentration of the analgesic drugs to be present at their sites of action in a shorter time.

In addition to a reduction in adverse effects, another advantage of a continuous epidural infusion over an epidural bolus injection is the ability to titrate the amount of analgesia; particularly shorter acting opioid like fentanyl is used. Fentanyl has an onset of action within 4 to 5 minutes and a peak effect within 20 minutes.10,11 Because of the rapid onset, it becomes much easier to adjust the dosage, to observe the desired effect, and titrate to an optimal intensity of analgesia. The continuous infusion also maintains a more constant intensity of analgesia. It can provide analgesia avoiding the peaks and nadir of pain sensation seen with intermittent bolus dose.

Lipophilic drug such as fentanyl tend to provide more of a segmental analgesic effect. This may in part be the result of lipophilic compounds partitioning into lipid compartments in the spinal canal, such as epidural fat and spinal cord. This segmental nature of analgesia mandates the need to place an epidural catheter in a location to cover the dermatomes included in surgical field. For orthopaedic operations in the lower extremities and lower abdominal and gynaecologic surgery, catheter has to be placed at lumbar region. Alternatively, catheter placement should be approximately at the dermatomal level that corresponds to a point intersecting the upper one-third and lower two-thirds of the surgical incision

Epidural co-administration of opioids with local anaesthetics takes advantage of the desirable properties of each drug. The desired result of these combinations are achievement of potentiated analgesia at lower opioid doses with diminished propensity for opioid induced ventilator depression. ${ }^{12}$ and a concentration of local anaesthetic that does not produce significant motor blockade.

This potentiation may be a result of antinociception at different sites in the spinal cord.13 Opioids produce analgesia by binding to opiate receptors in the substantia gelatinosa, whereas local anaesthetics block transmission of afferent impulses at the nerve roots and dorsal root ganglia. ${ }^{14}$ Another advantage of the combination using reduced doses is the concomitant decrease in the incidence and severity of side effects. Despite wide acceptance, not all studies have demonstrated analgesic potentiation when bupivacaine and fentanyl have been used in combination.

\section{CONCLUSION}

In conclusion, this study shows that combined bupivacaine and fentanyl infusion through an epidural route provides better analgesia in comparison to bupivacaine and fentanyl alone. Total drug administered in combined group is much less than that of isolated drug group. Rescue analgesic required in combined bupivacaine and fentanyl group is also less than that required in the isolated drug group. Regarding adverse effects, epidural administration of bupivacaine along with fentanyl dose not show any increase in adverse effect. So continuous epidural infusion of bupivacaine and fentanyl can be safely considered for prolonged and improved quality of analgesia in patients undergoing lower abdominal and lower extremity surgery.

\section{REFERENCES}

1. Paul G Barash, Bruce F Cullen, Robert K. Stoelting clinical Anaesthesia. $5^{\text {th }}$ edition:691-692.

2. Kehlet H, Dhal JB. The value of multimodal or balanced analgesia in postoperative pain relief. Anaesth Analg 1993;77:1048-1056.

3. Prithvi Raj P. Textbook of Regional Anaesthesia. Page 218-219.

4. Milon D, Lavenac G, Noury D, et al. Epidural anaesthesia during labour: comparison of 3 combinations of fentanylbupivacaine and bupivacaine alone. Ann Fr. Anaesth Reanim 1986;5(1):18-23.

5. Sintara RS, Goldstein R, Sevarino FB. The clinical effectiveness of epidural bupivacaine, bupivacaine with lidocaine, and bupivacaine with fentanyl for labour analgesia. J Clin Anaesth 1991;3(3):219-24; discussion 214-5.

6. Copper D, Turner G. Patient controlled extradural analgesia to compare bupivacaine, fentanyl and bupivacaine with fentanyl in treatment of postoperative pain. Br J Anesthesia 1993;70:503-7.

7. Bander NH, Bhandari R, Komar WE. Bupivacaine $0.125 \%$ improves continuous postoperative epidural fentanyl analgesia abdominal or thoracic surgery. Can J Anesth 1994;41:387-92.

8. Ozcan S, Tabuk M, Baltaci B, et al. Is epidural pre-emptive analgesia effective in El-Baz NM, Faber LP, Jensik RJ, Continuous epidural infusion of morphine for treatment of pain after thoracic surgery: a new technique. Anaesth Analg 63:757,1984 lower abdominal surgery? Agri 2004;16(1):58-63. 
9. El-Baz NM, Faber LP, Jensik RJ. Continuous epidural infusion of morphine, for treatment of pain after thoracic surgery: a new technique. Anaesth Analg 1984;63:75764.

10. Cousins MJ, Mather LE. Intrathecal and epidural administration of opioids. Anaesthesiology 1984;61(3):276-310.

11. Rutter DV, Skewes DG, Morgan M. Extradural opioids for postoperative analgesia. A double blind comparison of pethidine, fentanyl and morphine. $\mathrm{Br} \mathrm{J}$ Anaesth 1981;53(9):915-20.
12. Miller's anaesthesia. Spinal, epidural and caudal anaesthesia, Acute postoperative pain. $6^{\text {th }}$ edition:pp 2738-39, 2741.

13. Akerman B, Arwenstorm E, Post C. Local anaesthetic potentiates spinal morphine nociception. Anaesth Anal 1988;67(10):943-8.

14. Solomon RE, Gebhart GF. Synergistic antinociceptive interaction among drugs administered to the spinal cord. Anaesth Analg 1994;78:1164-72. 